\title{
Analysis of the scientific and organizational results of the Image Processing Systems Institute of the RAS
}

\author{
Kolomiets E.I.
}

Samara State Aerospace University

\begin{abstract}
This work summarizes milestones of research activity of the Image Processing Systems Institute of the Russian Academy of Sciences. Key research achievements of the Institute's team are depicted, staff members who have made an essential contribution to the Institute's success are acknowledged, and research areas of the Institute has been working in are outlined.
\end{abstract}

Keywords: scientific results, research institute, computer optics, image processing, diffractive nanophotonics, research directions, Russian Academy of Sciences

Citation: Kolomiets E.I. Analysis of the scientific and organizational results of the Image Processing Systems Institute of the RAS. Proceedings of Information Technology and Nanotechnology (ITNT-2015), CEUR Workshop Proceedings, 2015; 1490: 309-326. DOI: 10.18287/1613-0073-2015-1490-309-326

\section{Introduction}

This year we celebrate the 40th anniversary of the Computer Science Faculty of Samara State Aerospace University (National Research University) (SSAU) and the 70th anniversary of corresponding member of the Russian Academy of Sciences (RAS) Professor Victor A. Soifer. Presidium of the USSR Academy of Sciences (USSR AS) organized Kuibyshev branch of the Central Design Bureau of Unique Instrumentation (KB CDB UI) of the USSR AS on the basis of the research group headed by Professor Victor Soifer in 1988. This research group worked at the Computer Science Faculty of the Kuibyshev Aviation Institute (now - Samara State Aerospace University). KB CDB UI of the RAS was reorganized into the Image Processing Systems Institute of the RAS (IPSI RAS) five years later. Prof. Victor Soifer was director of the Institute since 1988 until January 2015. Now he is scientific leader of IPSI RAS. 2015 is the last year of the IPSI RAS work as an independent institution. At the end of 2015 IPSI RAS will become part of the Federal Research Center "Crystallography and Photonics". Looking back at the milestones of the Institute history, I would like to summarize key achievements of the Institute's team over the years passed. 


\section{The origins}

Late in the 70s of the last century, a research team at Kuibyshev Aviation Institute headed by professor V.A. Soifer actively collaborated with partners from the Institute of Information Transmission Problems of the RAS and P.N. Lebedev Physical Institute of the RAS. Those years were marked by obtaining basic research findings in areas such as digital image processing [1], focusing of light [2-5], generation of laser modes with desired transverse mode content [6-7], Bessel beams [8], and desired radiation directivity diagrams [9]; basics of computing experiment and asymptotic analysis in optics [10 - 13]. Following a host of articles jointly published in leading scientific Russian periodicals by V.A. Soifer, academician A.M. Prokhorov, professor I.N. Sisakyan, and their disciples [2-13], it became evident that at the interface of the research fields of cybernetics, quantum electronics, and microelectronics, a new research field was emerging, which became known as Computer, or Diffractive, Optics. In 1988, with the task to pursue research in the emerging area, the Kuibyshev branch of the Central Design Bureau of Unique Instrumentation of the USSR AS was established, with 60 people on the staff.

\section{Kuibyshev branch of the CDB of unique instrumentation}

The core of the KB CDB UI of the USSR Academy of Sciences was formed by young Candidates of Science: Ye.Yu. Arefiev, M.A. Golub, N.L. Kazanskiy, V.V. Kotlyar, O.V. Prisekina, and A.G. Khramov, with V.A. Soifer, Dr. of Eng., appointed director. Large organizational efforts associated with establishing the Branch were contributed by vice-director in charge of general issues Yu.N. Boyarkin and staff members L.P. Chepurnova, L.F. Egorova, Yu.A. Runkov, G.V. Uspleniev, Ye.D. Vasil'ev, D.M. Yakunenkova, and G.G Yamovich. The newly established KB CDB UI of the USSR Academy of Sciences was run as a self-sustained organization, with financing largely depending on the hunt for customers and commercial contracts for implementation of applied research projects. Notwithstanding the self-financing status, the basic research also stayed high on the list of priorities, which mainly became possible due to participation in the state-funded scientific \& technical programs, such as 'Advanced Information Technologies', 'High Technologies', and 'Samara's Conversion'. In the arduous 90s, taking part in the above-mentioned programs enabled the KB's research team to obtain and publish a number of cuttingedge research findings in the field of laser technology [14-16] and generation of laser beams with novel properties [17-19]. With the KB's key researchers (V.A. Soifer, V.V. Kotlyar, M.A. Golub, N.L. Kazanskiy, L.L. Doskolovich, S.N. Khonina) steering a course toward extensively publishing in leading foreign journals from the very beginning, the scientific school soon acquired the international recognition, which brought along first foreign contracts, also enabling M.A. Golub and V.V. Kotlyar to defend dissertations for Advanced Doctor's Degrees with flying colors in Moscow. Scientific and practical significance of the results obtained by Samara research team in collaboration with colleagues from Moscow (V.P. Shorin, V.A. Soifer, I.N. Sisakyan, V.A. Barvinok) brought them the 1992 RF State Prize for achievements in science and technology. 


\section{IPSI of the RAS}

Building on the success of the research team, V.A. Soifer - while enlisting the support of academicians S.V. Emelyanov, Yu.I. Zhuravlyev, and V.P. Shorin initiated the adoption of RAS Presidium's Resolution N 21 of January 26, 1993 by which the Samara branch of the CDB UI of the RAS was reorganized into the Image Processing Systems Institute of the RAS. Divisions on pattern recognition and image analysis were organized in the newly established Institute. Unfortunately, the Institute continued to be run on the self-support basis, which survived till 1998.

Nowadays, the IPSI RAS has 44 budget-funded positions, with the general number of employees (including part-timers) having reached 100 people. The Institute boasts 16 holders of Dr. of Sc. degree and 19 holders of Candidates of Sc. degree on the staff. The researchers with Doctor's Degree are 50 year-old on average, with Candidate's Degree - 35 year-old. All in all, there are 63 young researchers under 35 (including part-time workers, graduate and postgraduate students). 48 per cent of the total wage fund accounts for the salary of young scientists (under 35).

During the challenging formative years, the IPSI RAS managed to survive, later growing into a successful research institution, which was largely due to close integration with a leading Russian university - S.P. Korolyov Samara State Aerospace University (National Research University), below referred to as SSAU. Just after the KB CDB UI of the USSR AS was established, a joint Scientific \& Training Center (STC) 'Spectrum' was set up by the joint order N 167 (December 14, 1988) of the RSFSR Ministry of Higher Education and USSR AS. In the course of 25 years passed, the STC 'Spectrum' has been making rapid progress, making use of the opportunities offered by the RAS and federal programs aiming to promote the integration of basic research and higher education:

- 1997-2004: Participation, jointly with SSAU, in the federal program 'Integration of Basic Research and Higher Education';

- 2002-2012: Establishment and development of a Research \& Education Center of Mathematical Principles of Diffractive Optics and Image Processing as part of the Russian-American program 'Basic Research and Higher Education';

- 2006-2007: Participation in the SSAU Innovative Education program;

- since 2009: Taking part in the program of development of SSAU as a National Research University;

- since 2013: Taking part in the "5-100" program for improving the SSAU competitiveness.

The partnership between the IPSI RAS and SSAU has provided a stable influx of aspiring young researchers and professionals. The fruits of the collaboration include the establishment of new University subdepartments and joint Centers for collective use of research equipment [20], with highly challenging competitions won by joined effort and collaborative projects being under way currently. Further integration with SSAU may prove to be one of the ways to preserve the IPSI RAS research team now that the RAS has been reformed since 2013. 


\section{Research achievements}

The effectiveness of IPSI RAS' research activity can be evaluated in terms of the number of scientific articles published, the amount of grants won, and commercial contracts awarded.

Ever since its establishment, the number of publications by the Institute's researchers has exhibited a steady growth (Fig. 1). Noteworthy is not only the number of publications but also the journal titles where the articles have been published. Recent years have seen an increase in publications in the journals that have the Webof-Science impact-factor exceeding 3: Physics Review Letters [21], Applied Physics Letters [22], Optics Express [23-26], and Optics Letters [27-30]. In 2013, the journal Nature Communications published an article by D.A. Bykov and L.L. Doskolovich prepared by an international team of researchers with the participation of Moscow State University's scientists [31]. The IPSI researchers published 81 scientific articles in 2013 and 136 scientific articles in 2014 in the Editions indexed in the international database SCOPUS.

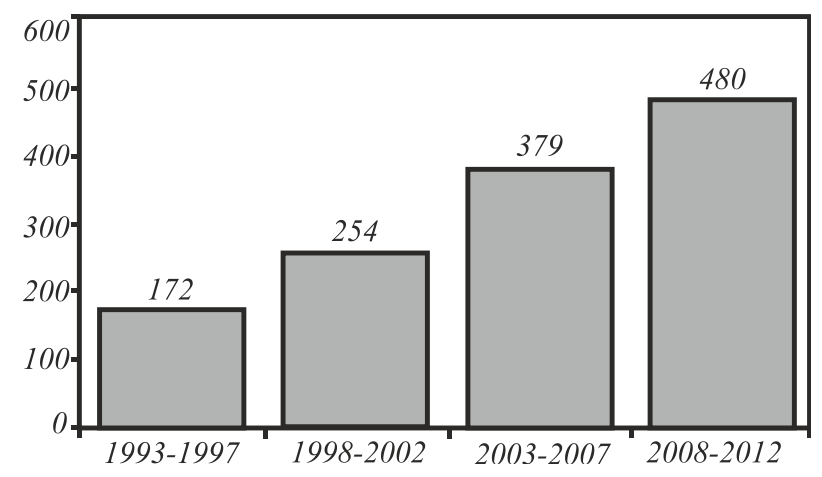

Fig. 1. - IPSI RAS: Publications dynamics

The interest in the research findings obtained by the IPSI RAS researchers is reflected in a high level of the articles' citation data. While Table 1 shows data according to the Russian Scientific Citation Index (RSCI), it should be noted that data on citations and Hirsh-indexes in Web of Science at V.A. Soifer, V.V. Kotlyar, and S.N. Khonina are not much different from those.

The research findings made by the IPSI scientists have also been summarized in a number of fundamental monographs published by recognized Publishing Houses around the world in the Russian, English [32-37], and Chinese languages [38]. Research topics covered by the monographs embrace all major IPSI's research areas from diffractive nanophotonics to medical imagery processing.

The research achievements widely recognized in the research community have enabled the IPSI's RAS scientists to win a host of Russian Foundation for Basic Research (RFBR) grants and RF Presidential grants (Fig. 2). For instance, out of three RF Presidential grants for Young Doctors of Science awarded in the field of information and telecommunication technologies in 2003, two grants were awarded to the IPSI researchers (L.L. Doskolovich and S.N. Khonina). Three young researchers of the IPSI 
RAS (D.A. Bykov, Ye.A. Bezus, A.V. Kuznetsov) get Russian President's Fellowships now. In 2014, three scientists of the IPSI RAS (L.L. Doskolovich, N.L. Kazanskiy, and R.V. Skidanov) won the Russian Science Foundation grants (2014-2016) for supporting research groups.

The bar charts in Fig. 3 present the number of Russian and international commercial contracts that IPSI RAS researchers have implemented over the last 15 years. Unfortunately, the world finance crisis has removed the international contracts from the agenda. However, thanks to active efforts undertaken at the domestic market the Institute landed two major Russian commercial contracts. One of them is to be implemented jointly with SSAU and aims to develop equipment for hyperspectral remote sensing [39-42] and tools for hyperspectral information processing [43 - 44] in the frame of the order of the space-missile center 'Progress' following RF Government's Resolution N 218. The other is concerned with the creation of compact vision systems for unmanned aircraft commissioned by the Research Institute for Applied Problems (Saint-Petersburg) [45-46].

Table 1. Citation indices of IPSI RAS leading researchers

\begin{tabular}{|c|c|c|c|}
\hline $\mathrm{N}$ & Name & RSCI & $\begin{array}{l}\text { Hirsh } \\
\text { index }\end{array}$ \\
\hline 1 & V. A. Soifer & 4814 & 29 \\
\hline 2 & N. L. Kazanskiy & 3036 & 26 \\
\hline 3 & V. V. Kotlyar & 2805 & 24 \\
\hline 4 & S. N. Khonina & 2775 & 24 \\
\hline 5 & L. L. Doskolovich & 2045 & 21 \\
\hline 6 & R. V. Skidanov & 1118 & 14 \\
\hline 7 & S. I. Kharitonov & 931 & 14 \\
\hline 8 & A. V. Volkov & 969 & 13 \\
\hline 9 & S. G. Volotovsky & 449 & 13 \\
\hline 10 & V. S. Pavelyev & 938 & 11 \\
\hline 11 & A.A. Kovalev & 508 & 11 \\
\hline 12 & D. L. Golovashkin & 647 & 10 \\
\hline 13 & V. V. Sergeev & 827 & 9 \\
\hline 14 & N. I. Glumov & 726 & 9 \\
\hline 15 & S. V. Karpeev & 412 & 9 \\
\hline 16 & D. A. Bykov & 277 & 9 \\
\hline 17 & Ye. A. Bezus & 269 & 9 \\
\hline 18 & V. A. Kolpakov & 291 & 8 \\
\hline 19 & A. V. Ustinov & 282 & 8 \\
\hline 20 & O. Yu. Moiseev & 254 & 8 \\
\hline 21 & P.G. Serafimovich & 219 & 8 \\
\hline 22 & N. Yu. Ilyasova & 672 & 7 \\
\hline 23 & A. G. Khramov & 629 & 7 \\
\hline 24 & S.B. Popov & 613 & 7 \\
\hline 25 & A.V. Kupriyanov & 171 & 7 \\
\hline 26 & M. A. Moiseev & 170 & 7 \\
\hline
\end{tabular}




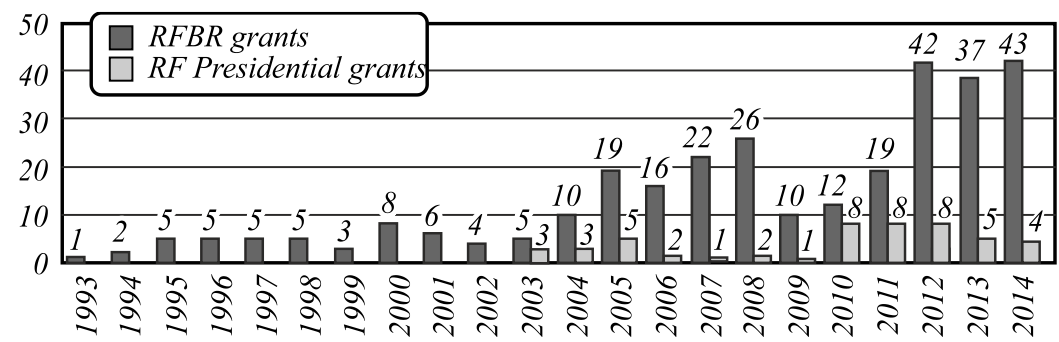

Fig. 2. - RFBR grants and RF President's grants

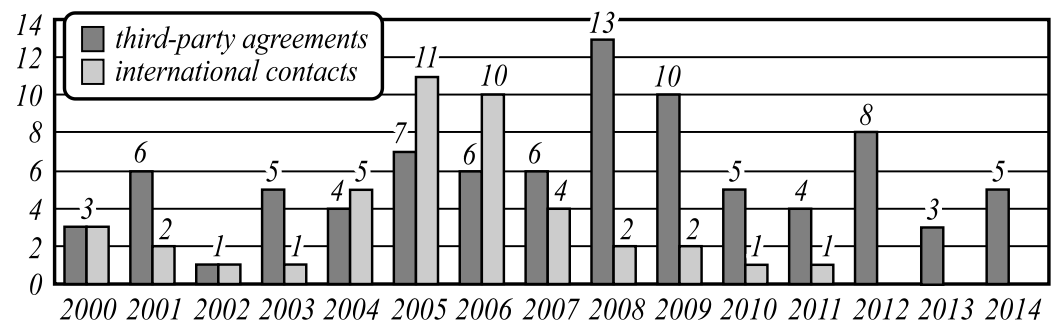

Fig. 3. - The bar chart shows successfully completed domestic and foreign commercial contracts

\section{Modern day}

Entering the RAS' division of Nano- and Information Technologies, the IPSI has been conducting research in the following fields, as approved by the RAS' Presidium Resolution N 37 of February 12, 2008:

- Computer/diffractive optics, nanophotonics, optical information technologies and systems;

- Systems for image analysis and pattern recognition;

- Geoinformation technologies.

In accordance with the Order of the Federal Agency of Scientific Organizations Professor N.L. Kazanskiy is temporarily working as acting director of the IPSI RAS since January 20, 2015. The IPSI RAS has four successful laboratories:

- Diffractive Optics (headed by Professor L.L. Doskolovich, Dr. of Phys. \& Math);

- Laser Measurements (headed by Professor V.V. Kotlyar, Dr. of Phys. \& Math);

- Micro- and Nanotechnologies (headed by Professor R.V. Skidanov, Dr. of Phys. \& Math);

- Mathematical Methods of Image Processing (headed by Professor V.V. Sergeev, Dr. of Eng.).

The scientific leader of IPSI RAS V.A. Soifer makes a point of encouraging his research team to always be involved in the cutting-edge research, with new areas including such subjects as, understanding and analysis of nanoscale object images [47- 
48], intelligent analysis of the Earth's remote sensing data [49-50], optical computing [24, 28, 29], chip-aided nanophotonic data processing [51-52], and so on.

Research work concerned with further development of methods and technologies for diffractive optics and image processing has also been successfully continued. Topics that have been actively developed include methods for designing diffractive focusing elements [53-59], methods for synthesizing the diffractive microrelief on various optical materials [60-67], computer-aided simulation technologies [68-74], and asymptotic diffraction research methods [75]. Methods for designing optical antennae have been put in practice for designing lighting devices [76-79], multi-order [80-81] and spectral [82-83] optical elements. Facilities and techniques for conducting optical experiments have been persistently improved [83-85], with the range of industrial application of laser light focusers considerably expanded [86]. New optical devices and machine vision systems have been created [87-92], the dedicated software for diffractive optics purposes has been developed [93], and methods for image processing and recognition proposed [94-97].

Annually, a number of research findings by the IPSI RAS researchers have been included into the list of achievements of the Russian Academy of Sciences (see Table 2 ). Among topics worthy of noting here are sharp focusing of laser light [98-100], new types of diffraction conditioners beams with unique properties [101-102], hyper-resonant magnetooptic effects in periodic nanoheterostructrues [21, 31, 103], focusing of the surface electromagnetic waves [22-23, 58-59], nanolithography techniques based on evanescent electromagnetic waves [63-64], new methods for image processing [43-50,91-92, 94-97, 104-106], and others.

Table 2. Number of IPSI RAS research findings included in the annual list of the Russian Academy of Sciences research achievements (RAS Reports)

\begin{tabular}{|c|c|c|c|c|c|c|c|c|c|}
\hline 2005 & 2006 & 2007 & 2008 & 2009 & 2010 & 2011 & 2012 & 2013 & 2014 \\
\hline 1 & 1 & 1 & 4 & 7 & 5 & 9 & 3 & 4 & 3 \\
\hline
\end{tabular}

As collaboration with SSAU, IPSI RAS publishes a journal of Computer Optics, which contains two major sections -- on optical technologies and image processing. The quarterly journal is peer-reviewed and indexed in international databases Scopus and Compendex. The most frequently cited journal articles [107-114] have been prepared mainly by the Institute's researchers. Now Computer Optics will be published every two months [115].

On a regular basis, the Institute hosts major regional international scientific conferences:

- "The IV-th workshop on Computer Optics", (February 19-24, 1990, Togliatti);

- 5th International Workshop on digital image processing and computer graphics "Image Processing and Computer Optics", (August 22-26, 1994. - Samara);

$-5^{\text {th }}$ international conference on "Pattern Recognition and Image Analysis" ("PRIA2000", October 16-22, 2000, Samara);

- International conference "Mathematical Modeling-2001", Chaired by academician A. A. Samarsky (June 13-16, 2001, Samara); 
- Fourth international scientific and practical seminar and All-Russian youth school "High-performance parallel computing using clusters" (September 30 - October 2, 2004, Samara);

- Seminar on "Computer Optics and Image Processing" to mark the 30-th anniversary of SSAU's Technical Cybernetics subdepartment and 20-th anniversary of IPSI RAS (June 20, 2008, Samara);

- Third international conference on Physics of Metals and Mechanics of Materials, Nanostructures, and Deformation Processes (June 3-5, 2009, Samara);

- International conference with taught courses for young researchers "Advanced Technologies for Aviation and Space" (“PIT-2010”, September 29 - October 1, 2010, Samara);

- Asia-Pacific Conference on Fundamental Problems of Opto- and Microelectronics (Москва-Самара, July 4-8, 2011, Moscow-Samara);

- 20th International Symposium "Nanostructures: Physics and Technology" (June 24-30, 2012, Nizhny Novgorod-Kazan-Saratov-Samara);

$-11^{\text {th }}$ International conference "Pattern recognition and Image Analysis: New Information Technologies" ("PRIA-11-2013», September 23-28, 2013, Samara).

Active research activity, organizing and hosting big international scientific events have been attracting an interest that prominent Russian and foreign scientists take in IPSI RAS researchers' works (as illustrated by Figs. 4-9).

\section{Public recognition}

As recognition of the successful research and economic activities, many IPSI RAS workers have been awarded various state and public awards.

In 1993, V.A. Soifer and S.N. Khonina were awarded the First Prize of the German Society for Support of Applied Informatics for the best research paper in image processing and pattern recognition. IPSI RAS director, V.A. Soifer was awarded the Honor Order (1995), the Orders for 'Services to Motherland' of IV-th (2004) and IIIrd (2010) degrees, RF Government's prizes for outstanding achievements in science and technology (2007) and in education (2010). In 2003, D.L. Golovashkin and V.S. Pavelyev were awarded the RF State Prize for Young Scientists. V.A. Soifer (2007), V.V. Kotlyar (2012), and S.N. Khonina (2014) were awarded the Governor's Prize of Samara region, 18 researchers (N.L. Kazanskiy, V.V. Kotlyar, V.V. Sergeev, 1998; V.M. Chernov, 1999; V.A. Soifer, V.A. Fursov, V.V. Kravchyuk, 2001; N.I. Glumov, N.Yu. Ilyasova, A.G. Khramov, 2003; A.V. Volkov, 2007; S.V. Karpeev, 2008; L.L. Doskolovich, 2009; S.N. Khonina, 2010; R.V. Skidanov, 2011; V.V. Myasnikov, 2012; S.I. Kharitonov, 2013; and S.B. Popov, 2014) become laureates of the Regional Prize in science and technology. V.A. Kolpakov (2011), D.A. Bykov and A.V. Gavrilov (2014) were awarded a RAS medal for young researchers, Ye.V. Byzov and S.V. Kravchenko were awarded a RAS medal for students in 2015. A.G. Khramov with colleagues from Samara Medical University was awarded the 2012 Gold medal of the International Inventions Exhibition in Geneva, Switzerland. V.A. Soifer was awarded the Scopus Award Russia 2014 and the title of "Honorary citizen of Samara Region". 


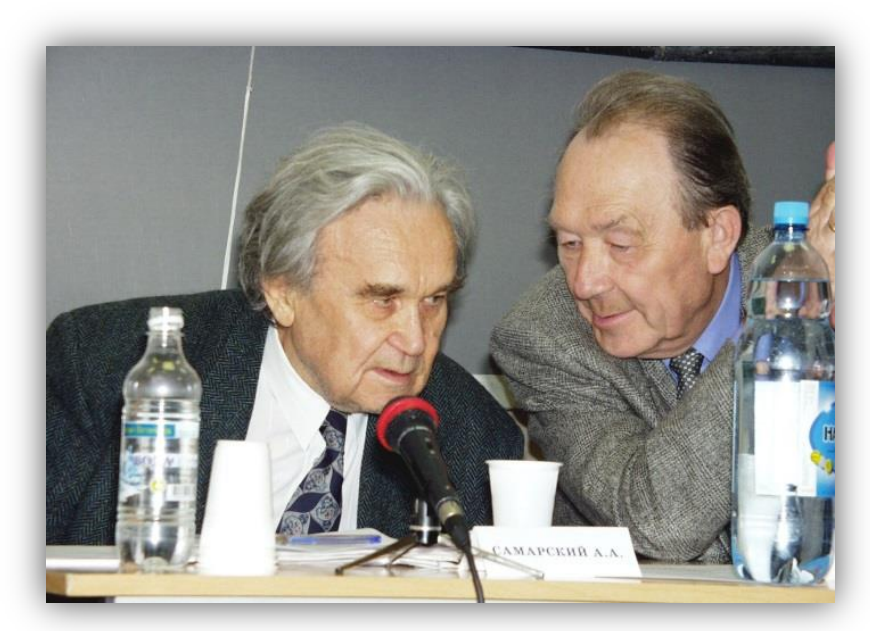

Fig. 4. - Presiding over the international conference "Mathematical Modeling-2001" are our illustrious contemporaries, academicians A.A. Samarsky (left) and Yu.I. Zhuravlev

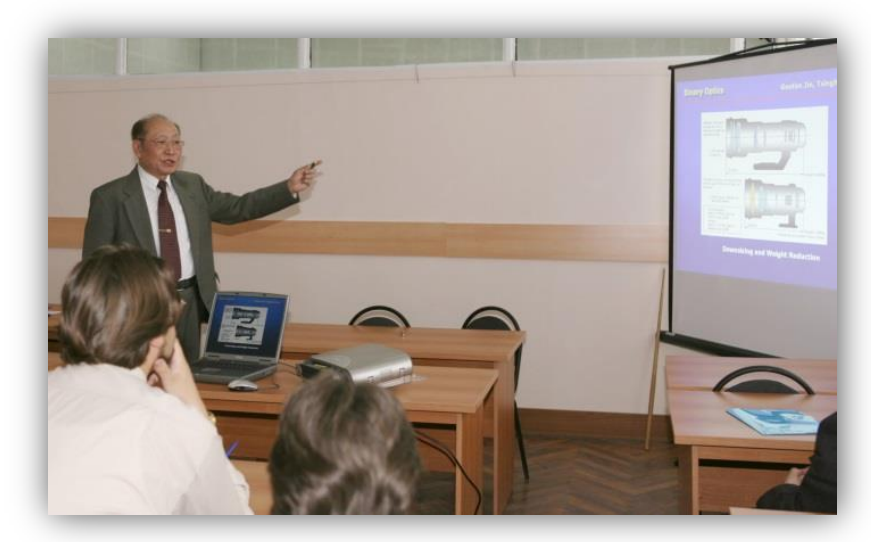

Fig. 5. - Vice-President of the International Commission in Optics (ICO), Prof. Jin Guofan of Tsinghua University delivers a lecture on "Binary Optics" at a seminar held at IPSI RAS on 8 September, 2006 


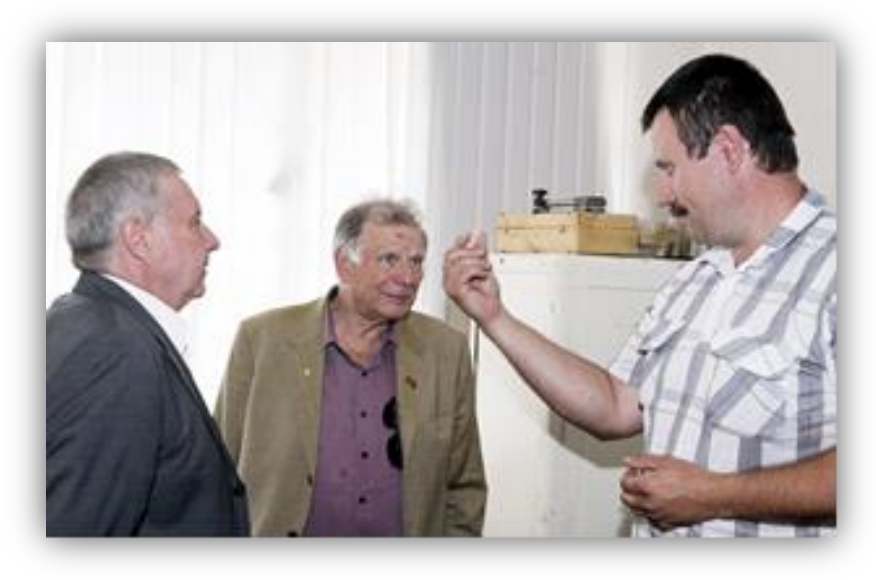

Fig. 6. - Prof. R.V. Skidanov presents a diffractive optical element for laser micromanipulation to academician J.I. Alferov (center) and the corresponding member of the RAS V.A. Soifer

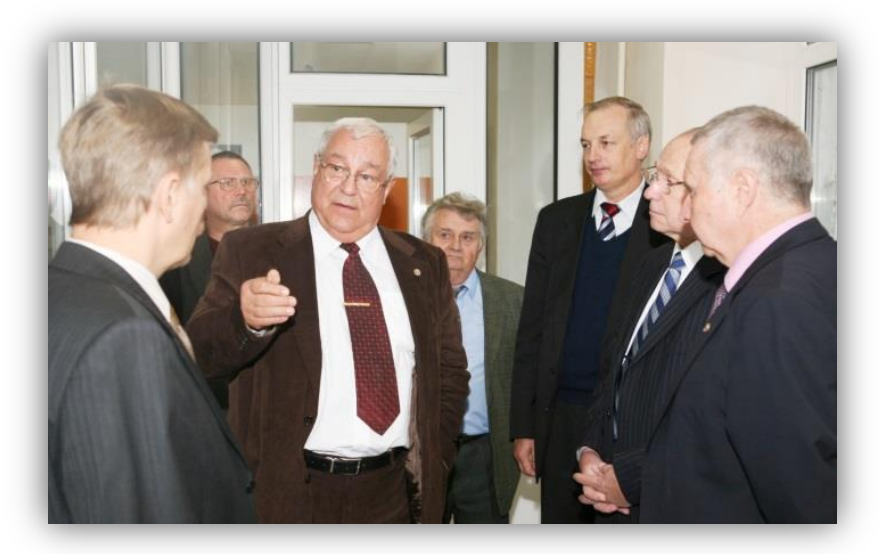

Fig. 7. - At the laboratory of Micro- and Nano-technologies (left to right): N.L. Kazanskiy, Yu.N. Boyarkin, academician Yu.V. Gulyaev, A.V. Volkov, SSAU Rector, Prof. Ye.V. Shakhmatov, academician G.V. Novozhilov, and the corresponding member of the RAS V.A. Soifer 


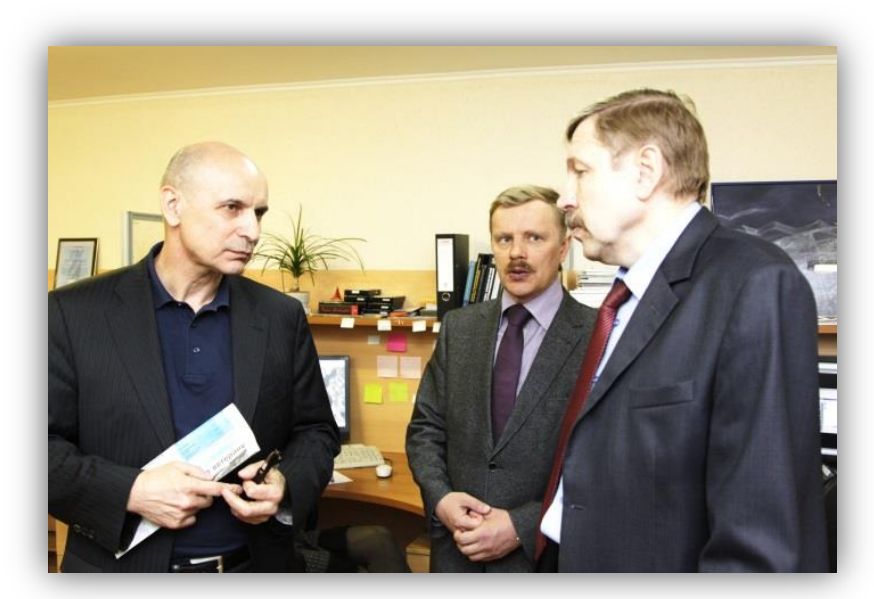

Fig. 8. - Chief Academic Secretary of the RAS Presidium, academician I.A. Sokolov (left) is discussing problems of steganography at the laboratory of Mathematical Methods of Image Processing with N.L. Kazanskiy (center) and V.V. Sergeev

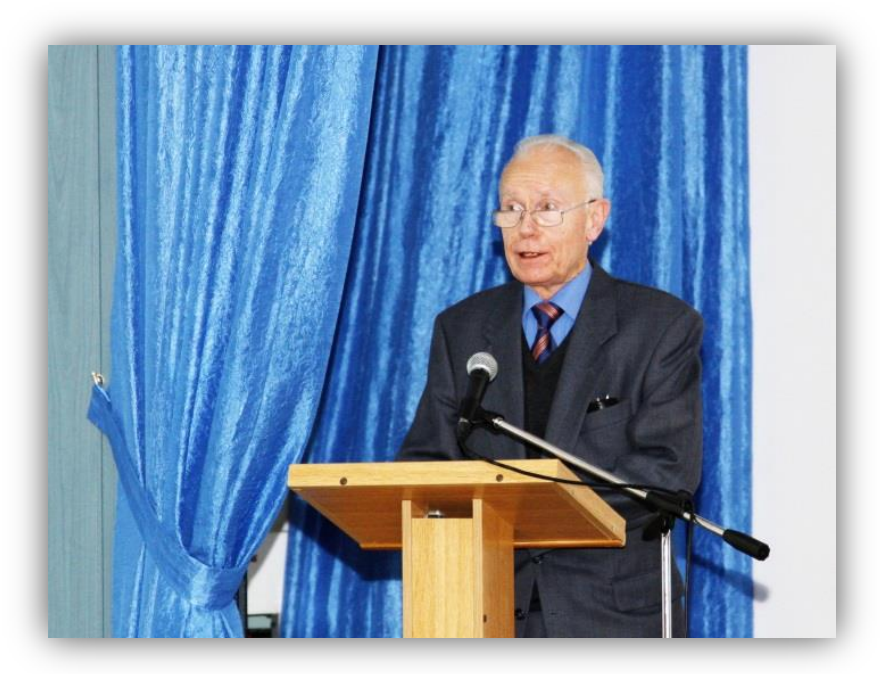

Fig. 9. - Professor Heinrich Niemann of the University of Erlangen-Nurenberg is greeting the IPSI RAS scientists at the $25^{\text {th }}$ anniversary celebration session of the International conference "PRIA-11-2013" on September 26, 2013

\section{Conclusion}

IPSI RAS is now the largest Russian scientific team working in the field of image processing and diffractive computer optics. IPSI RAS results largely determine the success of Russia in these scientific areas. Summing up, I wish the IPSI RAS

Information Technology and Nanotechnology (ITNT-2015) 
researchers to stay in good health, showing inexhaustible energy, insatiable scientific curiosity and new creative accomplishments for the benefit of our Motherland and Russian science!

\section{Acknowledgements}

I would like to thank the lead designer of IPSI RAS Yakov Takhtarov that provided wonderful pictures, and Chief Scientific Secretary of the Samara Scientific Center of the RAS Vladimir O. Sokolov for information about scientific results and the amounts of IPSI RAS.

\section{References}

1. Vittikh VA, Sergeyev VV, Soifer VA. Image processing in automated systems for scientific research. Moscow: "Nauka" Publisher, 1982. [in Russian]

2. Golub MA, Karpeev SV, Prokhorov AM, Sisakyan IN, Soifer VA. Focusing light into a specified volume by computer synthesized holograms. Soviet Technical Physics Letters, 1981; 7(10): 618-623.

3. Golub MA, Degtyarova VP, Klimov AN, Popov VV, Prokhorov AM, Sisakyan IN, Soifer VA. Machine synthesis of focusing elements for $\mathrm{CO}_{2}$-laser. Technical Physics Letters, 1982; 8(13): 449-451. [in Russian]

4. Danilov VA, Popov VV, Prokhorov AM, Sagatelyan DM, Sisakian IN, Soifer VA. Synthesis of optical elements that create focal free-form line. Technical Physics Letters, 1982; 8(13): 810-815. [in Russian]

5. Goncharskii V, Danilov VA, Popov VV, Prokhorov AM, Sisakian IN, Soifer VA, Stepanov VV. Solution of the inverse problem of laser-radiation focusing into an arbitrary curve. Doklady Akademii Nauk USSR, 1983; 273(3): 605-608. [in Russian]

6. Golub MA, Prokhorov AM, Sisakyan IN, Soifer VA. Synthesis of spatial filters for investigation of the transverse mode composition of coherent radiation. Soviet Journal of Quantum Electronics, 1982; 12(9): 1208-1209.

7. Golub MA, Karpeev SV, Kazanskii NL, Mirzov AV, Sisakyan IN, Soifer VA, Uvarov GV. Spatial phase filters matched to transverse modes. Soviet Journal of Quantum Electronics, 1988; 18(3): 392-393.

8. Bereznyi E, Prokhorov AM, Sisakyan IN, Soifer VA. Bessel-optics. Doklady Akademii Nauk USSR, 1984; 274(3): 605-608. [in Russian]

9. Golub MA, Kazanskii NL, Prokhorov AM, Sisakyan IN., Soifer VA. Synthesis of optical antennae. Computer Optics, 1989; 1(1): 25-28.

10. Golub MA, Kazanskiy NL, Sisakyan IN, Soifer VA, Kharitonov SI. Diffraction calculation for an optical element which focuses into a ring. Optoelectronics, Instrumentation and Data Processing, 1987; 6: 7-14.

11. Sisakyan IN, Soifer VA. Computer optics: achievements and problems. Computer Optics, 1989; 1(1): 3-12.

12. Golub MA, Kazanskii NL, Sisakyan IN, Soifer VA. Computational experiment with plane optical elements. Optoelectronics, Instrumentation and Data Processing, 1988; 1: 7889

13. Kazanskii NL. Correction of focuser phase function by computer-experimental methods. Computer Optics, 1989; 1(1): 69-73. 
14. Sisakyan N, Shorin VP, Soifer VA, Mordasov VI, Popov VV. Technological capabilities of focusators in laser-induced material processing. Computer Optics, 1990; 2(1): 85-87.

15. Golub MA, Sisakian IN, Soifer VA. Infra-red Radiation Focusators. Optics and Lasers in Engineering, 1991; 15(5): 297-309.

16. Doskolovich LL, Kazanskiy NL, Kharitonov SI, Usplenjev GV. Focusators for laserbranding. Optics and Lasers in Engineering, 1991; 15(5): 311-322.

17. Khonina SN, Kotlyar VV, Uspleniev GV, Shinkarev MV, Soifer VA. The phase rotor filter. Journal of Modern Optics, 1992; 39(5): 1147-1154.

18. Khonina SN, Kotlyar VV, Soifer VA, Shinkaryev MV, Uspleniev GV. Trochoson. Optics Communications, 1992; 91(3-4): 158-162.

19. Golub MA, Doskolovich LL, Kazanskiy NL, Kharitonov SI, Soifer VA. Computer generated diffractive multi-focal lens. Journal of Modern Optics, 1992; 39(6): 1245-1251.

20. Kazanskiy NL. Research \& Education Center of Diffractive Optics. Proceedings of SPIE, 2012; 8410: 84100R. doi: 10.1117/12.923233. 2012.

21. Belotelov VI, Doskolovich LL, Zvezdin AK. Extraordinary magneto-optical effects and transmission through metal-dielectric plasmonic systems. Physical Review Letters, 2007; 98(7): 077401.

22. Bezus EA, Doskolovich LL, Kazanskiy NL. Scattering suppression in plasmonic optics using a simple two-layer dielectric structure. Applied Physics Letters, 2011; 98(22): 221108. doi: 10.1063/1.3597620.

23. Bezus EA, Doskolovich LL, Kazanskiy NL. Low-scattering surface plasmon refraction with isotropic materials. Optics Express, 2014; 22(11): 13547-13554. doi: 10.1364/OE.22.013547.

24. Kazanskiy NL, Serafimovich PG. Coupled-resonator optical wave-guides for temporal integration of optical signals. Optics Express, 2014; 22(11): 14004-14013. doi: 10.1364/OE.22.014004.

25. Aslanov ER, Doskolovich LL, Moiseev MA, Bezus EA, Kazanskiy NL. Design of an optical element forming an axial line segment for efficient LED lighting systems. Optics Express, 2013; 21(23): 28651-28656.

26. Khonina SN, Savelyev DA, Kazanskiy NL. Vortex phase elements as detectors of polarization state. Optics Express, 2015; 23(14): 17845-17859. doi: 10.1364/OE.23.017845.

27. Kotlyar VV, Kovalev AA, Soifer VA. Asymmetric Bessel modes. Optics Letters, 2014; 39(8): 2395-2398.

28. Bykov DA, Doskolovich LL, Soifer VA. Temporal differentiation of optical signals using resonant gratings. Optics Letters, 2011; 36(17): 3509-3511.

29. Kazanskiy NL, Serafimovich PG, Khonina SN. Use of photonic crystal cavities for temporal differentiation of optical signals. Optics Letters, 2013; 38(7): 1149-1151. doi: 10.1364/OL.38.001149.

30. Golovastikov NV, Bykov DA, Doskolovich LL. Spatiotemporal pulse shaping using resonant diffraction gratings. Optics Letters, 2015; 40(15): 3492-3495. doi: 10.1364/OL.40.003492.

31. Belotelov VI, Kreilkamp LE, Akimov IA, Kalish AN, Bykov DA, Kasture S, Yallapragada VJ, Gopal AV, Grishin AM, Khartsev SI, Nur-E-Alam M, Vasiliev M, Doskolovich LL, Yakovlev DR, Alameh K, Zvezdin AK, Bayer M. Plasmon-mediated magneto-optical transparency. Nature Communications, 2013; 4 . doi: $10.1038 /$ ncomms 3128 .

32. Soifer VA, Golub MA. Laser Beam Mode Selection by Computer Generated Holograms. Boca Raton: CRC Press Inc, 1994. 
33. Soifer VA, Kotlyar VV, Doskolovich LL. Iterative methods for diffractive optical elements computation. London: Taylor and Francis Ltd, 1997.

34. Soifer VA, Kotlyar VV, Kazanskiy NL, Doskolovich LL, Kharitonov SI, Khonina SN, Pavelyev VS, Skidanov RV, Volkov AV, Golovashkin DL, Solovyev VS, Usplenyev GV. Methods for computer design of diffractive optical elements. Edited by Soifer VA. New York: John Wiley \& Sons, Inc, 2002.

35. Myasnikov VV, Popov SB, Sergeyev VV, Soifer VA. Computer Image Processing. Part I: Basic concepts and theory. Edited by Soifer VA. VDM Verlag, 2009.

36. Chernov AV, Chernov VM, Chicheva MA, Fursov VA, Gashnikov MV, Glumov NI, Ilyasova NYu, Khramov AG, Korepanov AO, Kupriyanov AV, Myasnikov EV, Myasnikov VV, Popov SB, Sergeyev VV, Soifer VA. Computer Image Processing. Part II: Methods and algorithms. Edited by Soifer VA. VDM Verlag; 2009.

37. Golovashkin DL, Doskolovich LL, Kazanskiy NL, Khonina SN, Kotlyar VV, Pavelyev VS, Skidanov RV, Soifer VA. Computer design of diffractive optics. Edited by Soifer VA. Cambridge International Science Publishing Ltd. \& Woodhead Pub. Ltd., 2012.

38. Doskolovich LL， Golovashkin DL， Kazanskiy NL， Khonina SN, Kotlyar VV, Pavelyev VS, Skidanov RV, Soifer VA, Solovyev VS, Usplenyev GV, Volkov AV. Methods for Computer Design of Diffractive Optical Elements. Edited by Soifer VA. Tianjin: Tianjin Science \& Technology Press, 2007. [in Chinese]

39. Kazanskiy NL, Kharitonov SI, Khonina SN, Volotovskiy SG, Strelkov YuS. Simulation of hyperspectrometer on spectral linear variable filters. Computer Optics, 2014; 38(2): 256-270. [in Russian]

40. Kazanskiy NL, Kharitonov SI, Karsakov AV, Khonina SN. Modeling action of a hyperspectrometer based on the offner scheme within geometric optics. Computer Optics, 2014; 38(2): 271-280. [in Russian]

41. Kazanskiy NL, Kharitonov SI, Khonina SN. Simulation of a hyperspectrometer based on linear spectral filters using vector Bessel beams. Computer Optics, 2014; 38(4): 770776. [in Russian]

42. Kazanskiy NL, Kharitonov SI, Doskolovich LL, Pavelyev AV. Modeling the performance of a spaceborne hyperspectrometer based on the Offner scheme. Computer Optics, 2015; 39(1). 70-76. [in Russian]

43. Denisova AYu, Myasnikov VV. Anomaly detection for hyperspectral imaginary. Computer Optics, 2014; 38(2): 287-296. [in Russian]

44. Gashnikov MV, Glumov NI. Hierarchical compression for hyperspectral image storage. Computer Optics, 2014; 38(3): 482-488. [in Russian]

45. Kazanskiy NL, Khonina SN, Skidanov RV, Morozov AA, Kharitonov SI, Volotovskiy SG. Formation of images using multilevel diffractive lens. Computer Optics, 2014; 38(3): 425-434. [in Russian]

46. Zherdev DA, Kazanskiy NL， Fursov VA， Kharitonov SI. Electromagnetic field scattering simulation from anthropogenic objects on underlying surface. Computer Optics, 2013; 37(1): 91-98. [in Russian]

47. Borodin SA, Volkov AV, Kazanskiy NL. Device for analyzing nanoroughness and contamination on a substrate from the dynamic state of a liquid drop deposited on its surface. Journal of Optical Technology, 2009; 76(7): 408-412.

48. Soifer VA, Kupriyanov AV. Analysis and recognition of the nanoscale images: conventional approach and novel problem statement. Computer Optics, 2011; 35(2): 136144. [in Russian] 
49. Gashnikov MV, Glumov NI, Sergeev VV. A hierarchical compression method for space images. Automation and Remote Control, 2010; 71(3): 501-513.

50. Zherdev DA, Kazanskiy NL, Fursov VA. Object recognition in radar images using conjugation indices and support subspaces. Computer Optics, 2015; 39(2): 255-264. [in Russian]

51. Kazanskiy NL, Serafimovich PG, Khonina SN. Harnessing the Guided-Mode Resonance to Design Nanooptical Transmission Spectral Filters. Optical Memory and Neural Networks (Information Optics), 2010; 19(4): 318-324. doi: 10.3103/S1060992X10040090.

52. Soifer VA. Diffractive Nanophotonics and Advanced Information Technologies. Herald of the Russian Academy of Sciences, 2014; 84(1): 9-18. doi: 10.1134/S1019331614010067.

53. Kazanskiy NL, Kotlyar VV, Soifer VA. Computer-aided design of diffractive optical elements. Optical Engineering, 1994; 33(10): 3156-3166.

54. Doskolovich LL, Kazanskiy NL, Soifer VA. Comparative analysis of different focusators focusing into a segment. Optics and Laser Technology, 1995; 27(4): 207-213.

55. Doskolovich LL, Kazanskiy NL, Soifer VA, Tzaregorodtzev AYe. Analysis of quasiperiodic and geometric optical solutions of the problem of focusing into an axial segment. Optik - International Journal for Light and Electron Optics, 1995; 101(2): 37-41.

56. Doskolovich LL, Kazanskiy NL, Kharitonov SI, Soifer VA. A method of designing diffractive optical elements focusing into plane areas. Journal of Modern Optics, 1996; 43(7): 1423-1433.

57. Soifer VA, Kazanskiy NL, Kharitonov SI. Synthesis of a Binary DOE Focusing into an Arbitrary Curve, Using the Electromagnetic Approximation. Optics and Lasers in Engineering, 1998; 29(4-5): 237-247.

58. Bezus EA, Doskolovich LL, Kazanskiy NL, Soifer VA, Kharitonov SI. Design of diffractive lenses for focusing surface plasmons. Journal of Optics, 2010; 12(1): 015001.

59. Bezus EA, Doskolovich LL, Kazanskiy NL, Soifer VA. Scattering in elements of plasmon optics suppressed by two-layer dielectric structures. Technical Physics Letters, 2011; 37(12): 1091-1095.

60. Volkov AV, Kazanskiy NL, Moiseev OYu, Soifer VA. A Method for the Diffractive Microrelief Forming Using the Layered Photoresist Growth. Optics and Lasers in Engineering, 1998; 29(4-5): 281-288.

61. Kazanskiy NL, Kolpakov VA, Kolpakov AI. Anisotropic Etching of $\mathrm{SiO}_{2}$ in HighVoltage Gas-Discharge Plasmas. Russian Microelectronics, 2004; 33(3): 169-182.

62. Pavelyev VS, Borodin SA, Kazanskiy NL, Kostyuk GF, Volkov AV. Formation of diffractive microrelief on diamond film surface. Optics \& Laser Technology, 2007; 39(6): 1234-1238.

63. Bezus EA, Doskolovich LL, Kazanskiy NL. Evanescent-wave interferometric nanoscale photolithography using guided-mode resonant gratings. Microelectronic Engineering, 2011; 88(2): 170-174.

64. Bezus EA, Doskolovich LL, Kazanskiy NL. Interference pattern formation in evanescent electromagnetic waves using waveguide diffraction gratings. Quantum Electronics, 2011; 41(8): 759-764.

65. Abulkhanov SR, Kazanskiy NL, Doskolovich LL, Kazakova OY. Manufacture of diffractive optical elements by cutting on numerically controlled machine tools. Russian Engineering Research, 2011; 31(12): 1268-1272.

66. Kazanskiy NL, Kolpakov VA, Podlipnov VV. Gas discharge devices generating the directed fluxes of off-electrode plasma. Vacuum, 2014; 101: 291-297. 
67. Volkov AV, Kazanskiy NL, Moiseev OYu, Poletayev SD. Thermal Oxidative Degradation of Molybdenum Films under Laser Ablation. Technical Physics, 2015; 60(2): 265-269. doi: 10.1134/S1063784215020255.

68. Kazanskiy NL, Soifer VA. Diffraction investigation of geometric-optical focusators into segment. Optik - International Journal for Light and Electron Optics, 1994; 96(4): 158162.

69. Golovashkin DL, Kazanskiy NL. Mesh Domain Decomposition in the Finite-Difference Solution of Maxwell's Equations. Optical Memory \& Neural Networks (Information Optics), 2009; 18(3): 203-211.

70. Khonina SN, Kazanskiy NL, Volotovsky SG. Influence of Vortex Transmission Phase Function on Intensity Distribution in the Focal Area of High-Aperture Focusing System. Optical Memory and Neural Networks (Information Optics), 2011; 20(1): 23-42. doi: 10.3103/S1060992X11010024.

71. Golovashkin DL, Kasanskiy NL. Solving Diffractive Optics Problem using Graphics Processing Units. Optical Memory and Neural Networks (Information Optics), 2011; 20(2): 85-89.

72. Khonina SN, Kazanskiy NL, Ustinov AV, Volotovskii SG. The lensacon: nonparaxial effects. Journal of Optical Technology, 2011; 78(11): 724-729.

73. Kazanskiy NL, Serafimovich PG. Cloud Computing for Rigorous Coupled-Wave Analysis. Advances in Optical Technologies, 2012. doi: 10.1155/2012/398341.

74. Kazanskiy NL, Serafimovich PG. Cloud Computing for Nanophotonic Simulations. Lecture Notes in Computer Science, 2013; 7715: 54-67.

75. Kazanskiy NL, Kharitonov SI, Soifer VA. Application of a pseudogeometrical optical approach for calculation of the field formed by a focusator. Optics \& Laser Technology, 1996; 28(4): 297-300.

76. Doskolovich LL, Kazanskiy NL, Soifer VA, Kharitonov SI, Perlo P. A DOE to form a line-shaped directivity diagram. Journal of Modern Optics, 2004; 51(13): 1999-2005.

77. Doskolovich LL, Kazanskiy NL, Kharitonov SI, Perlo P, Bernard S. Designing reflectors to generate a line-shaped directivity diagram. Journal of Modern Optics, 2005; 52(11): 1529-1536.

78. Doskolovich LL, Kazanskiy NL, Bernard S. Designing a mirror to form a line-shaped directivity diagram. Journal of Modern Optics, 2007; 54(4): 589-597.

79. Doskolovich LL, Dmitriev AYu, Moiseev MA, Kazanskiy NL. Analytical design of refractive optical elements generating one-parameter intensity distributions. Journal of the Optical Society of America A, 2014; 31(11): 2538-2544. doi: 10.1364/JOSAA.31.002538.

80. Soifer VA, Doskolovich LL, Kazanskiy NL. Multifocal diffractive elements. Optical Engineering, 1994; 33(11): 3610-3615.

81. Doskolovich LL, Kazanskiy NL, Perlo P, Repetto P, Soifer VA. Direct two-dimensional calculation of binary DOEs using a non-binary series expression approach. International Journal of Optoelectronics, 1996; 10(4): 243-249.

82. Doskolovich LL, Kazanskiy NL, Soifer VA, Perlo P, Repetto P. Design of DOEs for wavelength division and focusing. Journal of Modern Optics, 2005; 52(6): 917-926.

83. Doskolovich LL, Kazanskiy NL, Khonina SN, Skidanov RV, Heikkila N, Siitonen S, Turunen J. Design and investigation of color separation diffraction gratings. Applied Optics, 2007; 46(15): 2825-2830.

84. Kazanskiy N, Skidanov R. Binary beam splitter. Applied Optics, 2012; 51(14): 26722677. 
85. Bezus EA, Morozov AA, Volodkin BO, Tukmakov KN, Alferov SV, Doskolovich LL. Formation of High-Frequency Two-Dimensional Interference Patterns of Surface Plasmon Polaritons. Journal of Experimental and Theoretical Physics Letters, 2013; 98(6): 317-320.

86. Kazanskiy NL, Murzin SP, Osetrov YeL, Tregub VI. Synthesis of nanoporous structures in metallic materials under laser action. Optics and Lasers in Engineering, 2011; 49(11): 1264-1267.

87. Karpeev SV, Pavelyev VS, Khonina SN, Kazanskiy NL, Gavrilov AV, Eropolov VA. Fibre sensors based on transverse mode selection. Journal of Modern Optics, 2007; 54(6): 833-844. doi:10.1080/09500340601066125.

88. Egorov AV, Kazanskiy NL, Serafimovich PG. The use coupled photonic crystal cavities for increasing of sensor sensitivity. Computer Optics, 2015; 39(2): 158-162.

89. Kazanskiy NL, Popov SB. Machine Vision System for Singularity Detection in Monitoring the Long Process. Optical Memory and Neural Networks (Information Optics), 2010; 19(1): 23-30.

90. Kazanskiy NL, Murzin SP, Tregub VI. Optical system for realization of selective laser sublimation of metal alloy components. Computer Optics, 2010; 34(4): 481-486. [in Russian]

91. Kazanskiy NL, Popov SB. The distributed vision system of the registration of the railway train. Computer Optics, 2012; 36(3): 419-428. [in Russian]

92. Kazanskiy NL, Popov SB. Integrated Design Technology for Computer Vision Systems in Railway Transportation. Pattern Recognition and Image Analysis, 2015; 25(2): 215-219. doi: 10.1134/S1054661815020133.

93. Doskolovich LL, Golub MA, Kazanskiy NL, Khramov AG, Pavelyev VS, Seraphimovich PG, Soifer VA, Volotovskiy SG. Software on diffractive optics and computer generated holograms. Proceedings of SPIE, 1995; 2363: 278-284.

94. Chernov VM. Fast algorithm for "error-free" convolution computation using MersenneLucas codes. Chaos, Solitons \& Fractals, 2006; 29(2): 372-380.

95. Myasnikov VV. Constructing efficient linear local features in image processing and analysis problems. Automation and Remote Control, 2010; 71(3): 514-527.

96. Kuznetsov AV, Myasnikov VV. A comparison of algorithms for supervised classification using hyperspectral data. Computer Optics, 2014; 38(3): 494-502. [in Russian]

97. Kazanskiy NL, Protsenko VI, Serafimovich PG. Comparison of system performance for streaming data analysis in image processing tasks by sliding window. Computer Optics, 2014; 38(4): 804-810. [in Russian]

98. Stafeev SS, O'Faolain L, Shanina MI, Nalimov AG, Kotlyar VV. Sharp focusing of a mixture of radially and linearly polarized beams using a binary microlens. Computer Optics, 2014; 38(4): 606-613. [in Russian]

99. Degtyarev SA, Ustinov AV, Khonina SN. Nanofocusing by sharp edges. Computer Optics, 2014; 38(4): 629-637. [in Russian]

100. Khonina SN, Kazanskiy NL, Volotovsky SG. Vortex phase transmission function as a factor to reduce the focal spot of high-aperture focusing system. Journal of Modern Optics, 2011; 58(9): 748-760. doi: 10.1080/09500340.2011.568710.

101. Kotlyar VV, Kovalev AA, Zaskanov SG. Two-dimensional accelerating Bessel beams. Computer Optics, 2014; 38(3): 386-392. [in Russian]

102. Kotlyar VV, Kovalev AA, Porfirev AP. Hermite-gaussian laser beams with orbital angular momentum. Computer Optics, 2014; 38(4): 651-657. [in Russian]

103. Bykov DA, Doskolovich LL, Soifer VA, Kazanskiy NL. Extraordinary Magneto-Optical Effect of a Change in the Phase of Diffraction Orders in Dielectric Diffraction Gratings. Journal of Experimental and Theoretical Physics, 2010; 111(6): 967-974. 
104. Zimichev EA, Kazanskiy NL, Serafimovich PG. Spectral-spatial classification with kmeans particional clustering. Computer Optics, 2014; 38(2): 281-287. [in Russian]

105. Zherdev DA, Kazanskiy NL, Fursov VA. Object recognition by the radar signatures of electromagnetic field scattering on base of support subspaces method. Computer Optics, 2014; 38(3): 503-510.

106. Ilyasova NYu, Kupriyanov AV, Paringer RA. Formation features for improving the quality of medical diagnosis based on the discriminant analysis methods. Computer Optics, 2014; 38(4): 851-855. [in Russian]

107. Volkov AV, Kazanskiy NL, Rybakov OE. Investigation of plasma etching technology for producing multilayer diffractive optical elements. Computer Optics, 1998; 18: 127-130. [in Russian]

108. Volkov AV, Kazanskiy NL, Rybakov OE. Development of technology for creation of diffractive optical elements with submicron dimensions of the relief in the silicon wafer. Computer Optics, 1998; 18: 130-133. [in Russian]

109. Kazanskiy NL. A research complex for solving problems of computer optics. Computer Optics, 2006; 29: 58-77. [in Russian]

110. Kazanskiy NL, Murzin SP, Tregub VI, Mezhenin AV. Application of a focusator radiation for generating nanoporous structures of crystalline materials. Computer Optics, 2007; 31(2): 48-51. [in Russian]

111. Kazanskiy NL, Murzin SP, Mezhenin AV, Osetrov EL. Laser radiation shaping for creation nanodimensional porous structures of materials. Computer Optics, 2008; 32(3): 246-248. [in Russian]

112. Kotlyar VV, Stafeev SS. Modeling the sharp focus of radially polarized laser mode with conical and binary microaxicons. Computer Optics, 2009; 33(1): 52-60. [in Russian]

113. Khonina SN, Volotovsky SG. Controlling the contribution of the electric field components to the focus of a high-aperture lens using binary phase structures. Computer Optics, 2010; 34(1): 58-68. [in Russian]

114. Zvekov AA, Kalenskii AV, Nikitin AP, Aduev BP. Radiance distribution simulation in a transparent medium with Fresnel boundaries containing aluminum nanoparticles. Computer Optics, 2014; 38(4): 749-756. [in Russian]

115. Soifer VA. Quo vadis. Computer Optics, 2014; 38(4): 589. 